\title{
EL MURAL DE FRANCISCO SEBASTIÁN EN LA ESCUELA DE MAGISTERIO DE LOGROÑO
}

\author{
Adolfo López \\ Doctorando, Universidad de La Rioja \\ adlfes@yahoo.es
}

RESUMEN: En el salón de actos de la Escuela de Magisterio de Logroño existió un mural realizado por el pintor Francisco Sebastián Rodríguez. Fue un reconocido pintor valenciano nacido en 1920, además de profesor, decorador y muralista. El artículo sitúa al mural en el contexto muralista nacional y regional de los años 50, y analiza el gran mural de Logroño, oculto tras las diversas reformas del edificio, analizando su temática y sus características formales.

Palabras clave: Francisco Sebastián, mural, muralismo, Logroño, Escuela de Magisterio.

\section{FRANCISCO SEBASTIAN'S MURAL AT THE TEACHER'S TRAINING SCHOOL IN LOGROÑO}

ABSTRACT: It stood a mural in the auditorium of the Education School in Logroño by the painter Francisco Sebastian Rodriguez. He was a renowned valencian painter, professor, decorator and muralist born in 1920. The article places the mural in a historical context and focuses on the large mural of Logroño, hidden in its original location, analyzing its thematic and formal characteristics.

Keywords: Francisco Sebastian, mural, muralism, Logroño, Escuela de Magisterio.

Recibido: 24 de Julio de 2017 Aceptado: 24 de Septiembre de 2107 
Cuando estudiaba E.G.B en la Escuela Aneja de Magisterio de Logroño a veces nos llevaban al salón de actos y allí me llamaba la atención una enorme pintura situada en la parte superior del escenario'. Pasados los años, tras varias reformas en el edificio, comprobé que no quedaba ningún rastro del citado mural. Quise averiguar algo más sobre aquella pintura para que no cayera en el olvido definitivo y la casualidad me llevó, a través de internet, a encontrar varias fotografías que correspondían con la imagen que había quedado guardada en mis recuerdos y que me han servido como punto de partida para realizar este artículo.

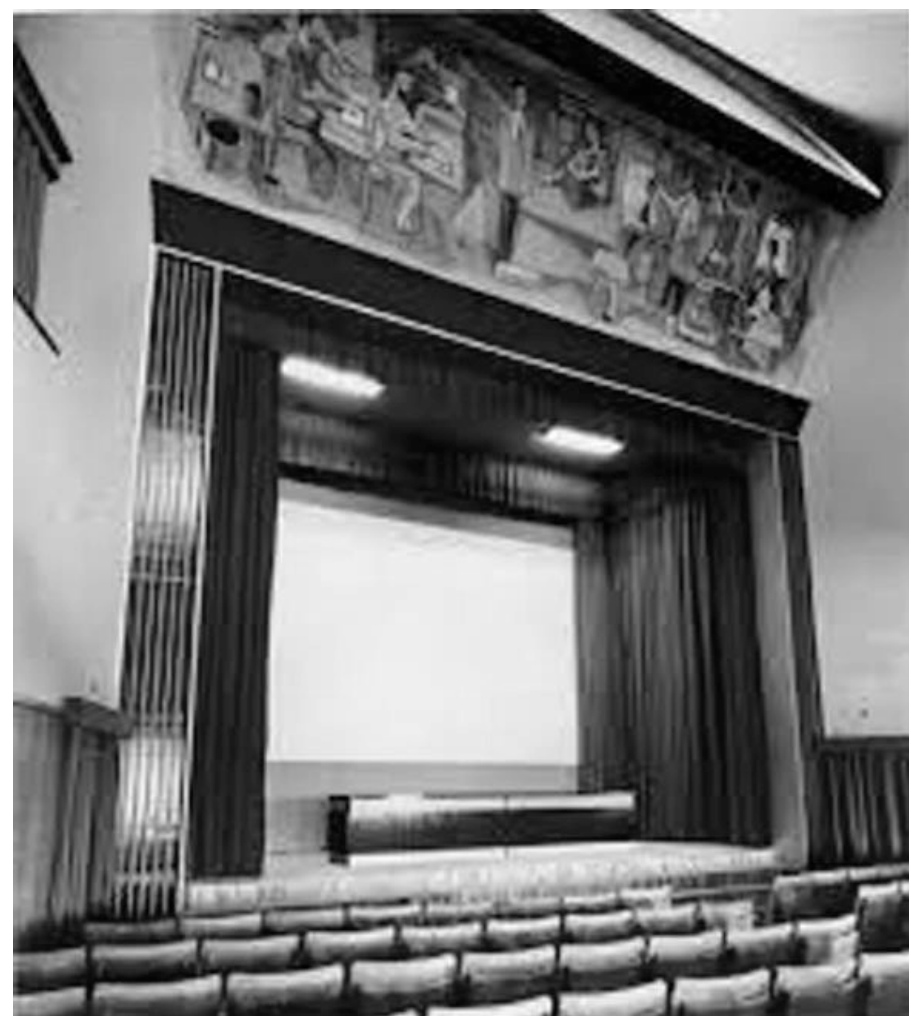

LÁmina 1. Escenario y mural del salón de actos de la Escuela de Magisterio de Logroño.

1. Fuente de las láminas 1 y 3: http://archivodeautores.cdicv.com. Consulta: (18/03/2015). Esta página web, perteneciente al Colegio de Diseñadores de Interior de la Comunidad Valenciana, fue retirada, quedando en internet tres imágenes sueltas sin enlace a la misma; aunque eran de muy baja resolución, se ha considerado de interés para este trabajo adjuntar dos de ellas. 
Siguiendo la tesis doctoral de María Luisa Grau Tello², la pintura mural en España tuvo un momento álgido desde los años cuarenta a los sesenta, con múltiples ejemplos públicos y privados, propiciado por la reivindicación de la integración de arquitectura, escultura y pintura. La idea fue defendida tanto por arquitectos, críticos o artistas plásticos (Parpalló y Equipo 57) como por el régimen franquista, aunque con motivaciones diametralmente diferentes.

En general, la pintura mural promovida por las diferentes administraciones tuvo una lectura política, de exaltación de valores patrióticos como la familia, el esfuerzo en equipo, la unidad o la religiosidad, que iría cambiando a lo largo de la década de los cincuenta al ir integrándose España en las estructuras internacionales.

Por otra parte, la pintura mural de iniciativa privada tuvo su gran momento en los años cincuenta con la salida de la depresión y el estrechamiento de lazos con Estados Unidos. El incremento de negocios para vender los nuevos productos y el auge del tiempo de ocio propiciaron la necesidad de competir para atraer al nuevo consumidor y con ello la de destacar a través de la decoración de bares, restaurantes, tiendas o cines y en ese juego entraron los arquitectos, decoradores, pintores muralistas o cartelistas, escaparatistas ${ }^{3}$.

Dentro del panorama nacional, la ciudad de Logroño no quedó ajena a este renacer muralista impulsado por los diferentes organismos públicos, aunque los ejemplos de este género artístico fueron muy escasos. En los años cincuenta el pintor Francisco Sebastián recibió el encargo del Ministerio de Educación de realizar un mural para la nueva Escuela de Magisterio y el cántabro, Fernando Sáez González, ayudado por su hermano Martín, Ilevó a cabo, hacia 1955, dos murales para la desaparecida estación de ferrocarril de la ciudad (actualmente recogidos en un almacén) ${ }^{4}$.

Tanto los lienzos de Sáenz como el mural de Francisco Sebastián transitaron por territorios comunes: el trasfondo ideológico promovido por el régimen se evidencia en la exaltación de la grupalidad, del esfuerzo o el nuevo papel de la mujer; formalmente muestran semejanzas en la simplicidad y la serenidad de las figuras o en la uniformidad de los colores, además, en ambos casos, la obra de Picasso aparece como una evidente influencia.

En cuanto al ámbito privado logroñés, es preciso reseñar los murales realizados, entre los años treinta y cuarenta, por el madrileño, de ascendencia riojana, Francisco Javier Rodríguez Garrido. La mayoría de ellos se encuentran

2. Grau Tello, M. L., La pintura mural en la esfera pública de Zaragoza, 1950-1997. Tesis Doctoral, Departamento de Historia del Arte de la Facultad de Filosofía y Letras de la Universidad de Zaragoza. Zaragoza, 2012, pp. 51-62.

3. Grau Tello, M. L., La pintura mural en..., op. cit. pp. 107-112.

4. López Fernández, A., "La estación de ferrocarril de Logroño". Piedra de Rayo, no 31. Logroño. 2009, pp. 44-57. 
desaparecidos, al igual que los locales que decoraban (El Cine Diana y el Café Los Leones) conservándose únicamente las alegorías de Las cuatro estaciones, resueltas en un estilo decorativista, y que están emplazadas en las fachadas del edificio de viviendas $n^{0} 53$ de la calle Duquesa de La Victoria ${ }^{5}$.

\section{El mural de la Escuela de Magisterio}

En 1959 Francisco Sebastián Rodríguez recibió el cometido de pintar un gran mural ${ }^{6}$ para la Escuela de Magisterio de Logroño. La única referencia a este encargo es la copia de un párrafo de una carta, de fecha 11 de diciembre de 1959, en la que el arquitecto Francisco Navarro Borrás hace varios comentarios al boceto presentado por el autor. En general parece de su agrado pero matiza que "la alegoría no debe referirse a los niños de las escuelas graduadas, sino a los maestros y maestras; o mejor a los alumnos de las Normales. Por esto en la composición deben figurar también chicas, y asimismo debe tenerse en cuenta las disciplinas de su formación; es decir que a la vez que se incluyen cartabones, compases y otros elementos, deberá existir alguna referencia a las disciplinas artísticas (música, dibujo) o a elementos de laboratorio... o a la Pedagogía, libros, rollos, etc. En fin, comprendo que el asunto es difícil, pero Sebastián es persona de talento, y ya me entenderá. El estilo actual de la técnica me parece bien." ${ }^{\prime 7}$

Francisco Navarro Borrás ${ }^{8}$, tenía el cargo de Arquitecto Jefe de la Oficina Técnica para Construcción de Escuelas del Ministerio y fue el arquitecto respon-

5. Este edificio fue levantado en 1929 por su cuñado el arquitecto Agapito del Valle. Otros locales de Logroño en los que dispuso sus murales fueron: Café Los Leones, en 1941 realizó al óleo sobre escayola varias escenas galantes; Cine Diana, hacia 1941 pintó un friso semicircular, que enmarcaba la pantalla, con escenas cinegéticas y ecuestres. Gil-Díez Usandizaga. I., "Pintura del siglo XX" en Moya Valgañón, J.G., (dir.). Historia del arte en La Rioja V, Los siglos XIX y XX. Logroño, 2006, pp. 267-268 y 273. Heras y Núñez, M. de los Á., "Francisco Javier Rodríguez Garrido", en Piudo, M. (coord.). En Personas y personajes: 150 aniversario del Instituto de Bachillerato Práxedes Mateo Sagasta. Logroño, 1994, pp. 221-222. En la página web http://www.valvanera.com/rirodriguez.htm (Consulta: 12/09/2016) se menciona la siguiente información que no se ha podido contrastar en ninguna otra fuente: “...en el desaparecido Hotel París, entre 1934 y 1935, pintó siete murales en sus bajos. De grandes dimensiones, algunos alcanzaban los seis metros de longitud. Estaban realizados sobre escayola y montados en un armazón de madera."

6. Fuente de la lámina 2: http://pintura.aut.org/SearchProducto?Produnum=121019 (Consulta: $13 / 12 / 2015)$.

7. Clérigues Peris, M. V., El Lenguaje Plástico en la Obra de Francisco Sebastián Rodríguez: De lo Racional y lo Emocional. Tesis Doctoral, Facultad de Bellas Artes de la Universidad Politécnica de Valencia, Valencia, 2003, Apéndice documental, B-33.

8. Nacido en Reus en 1905, estudió las carreras de Ciencias Químicas y Ciencias Exactas y un año más tarde obtuvo el título de Arquitecto de la Escuela Superior de San Fernando, de Madrid. A partir de 1939 desempeñó, entre otros, los cargos de Arquitecto 
sable de la construcción de la Escuela de Magisterio de Logroño ${ }^{9}$. Por la forma de redacción de la carta, parece ser que Navarro Borrás no se dirigió a Sebastián directamente aunque sabía de su valía artística, sería quizás a través de un tercero la manera de trasladarle sus sugerencias, desconociendo el conducto que se utilizó desde la administración central para contactar con el pintor y realizarle el encargo.

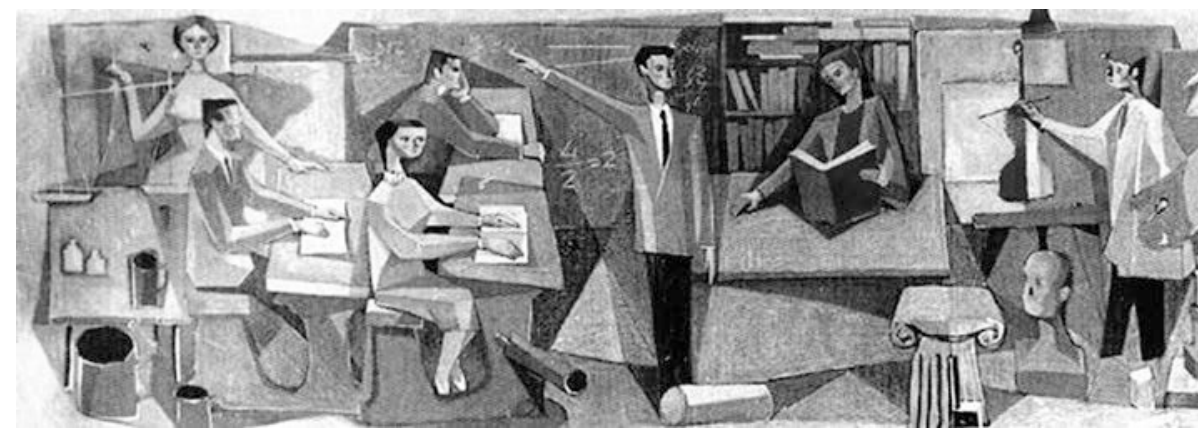

LÁMINA 2. Mural.

Del texto se deduce que, en un primer momento, Sebastián habría enfocado el tema para que los protagonistas fueran los alumnos, aunque posteriormente recogió todas las sugerencias de Navarro: la inclusión de estudiantes de Magisterio en vez de niños, las referencias tanto a asignaturas artísticas como científicas, al igual que la introducción de mujeres como futuras profesoras.

El mural fue emplazado sobre el escenario del salón de actos, ligeramente inclinado hacia adelante para una mejor visualización dada la gran distancia a la que se elevaba. Según los planos que se conservan del recinto ${ }^{10}$ las dimensiones aproximadas del mural alcanzarían los 8,50 metros de largo por 2,50 metros de ancho. (Lámina 1)

del Ministerio de Justicia, Consejero Nacional de Educación (1941) y Arquitecto Jefe de la Oficina Técnica para Construcción de Escuelas del Ministerio (1941), este último le llevó a realizar y dirigir diferentes proyectos de edificios educativos durante los años cincuenta, entre ellos la Escuela de Magisterio de Jaén (1955), la de Castellón (1957) o la ampliación de la de León (1960).

9. Archivo General de la Administración (en adelante AGA), Alcalá de Henares, IDD (05)001.018, caja 32/00303: Proyecto de terminación de Escuela Normal de Magisterio Primario en Logroño - Año 1932. IDD (05)001.018, caja 32/00547: Proyecto de edificio de Escuela del Magisterio, Escuelas Graduadas y cuatro viviendas para subalternos en Logroño - Año 1956. Existe un proyecto inicial de diciembre de 1950 y otro proyecto definitivo de noviembre de 1956. El presupuesto fue de16.231.877,12 pesetas (6 de abril de 1957). Las pistas y frontón son de otro proyecto de marzo 1962.

10. Archivo Municipal de Logroño, (en adelante AMLO), 1007/93. 
Una fotografía antigua, donde aparece el autor junto a su mural antes de ser emplazado en su espacio definitivo, sirve para confirmar que sería pintado en un gran estudio de su localidad, aunque no se ha podido averiguar su ubicación concreta, y que posteriormente sería trasladado y adherido al muro definitivo. (Lámina 3)

El artista empleó la técnica del óleo sobre un único lienzo de lino de grandes dimensiones, ambos elementos parecen idóneos para que en su traslado y colocación la obra no sufriera deterioros importantes, lo que, en principio, hace pensar que el autor no hubiera tenido necesidad de desplazarse hasta la ciudad de Logroño para controlar el resultado final o para realizar retoques de pintura.

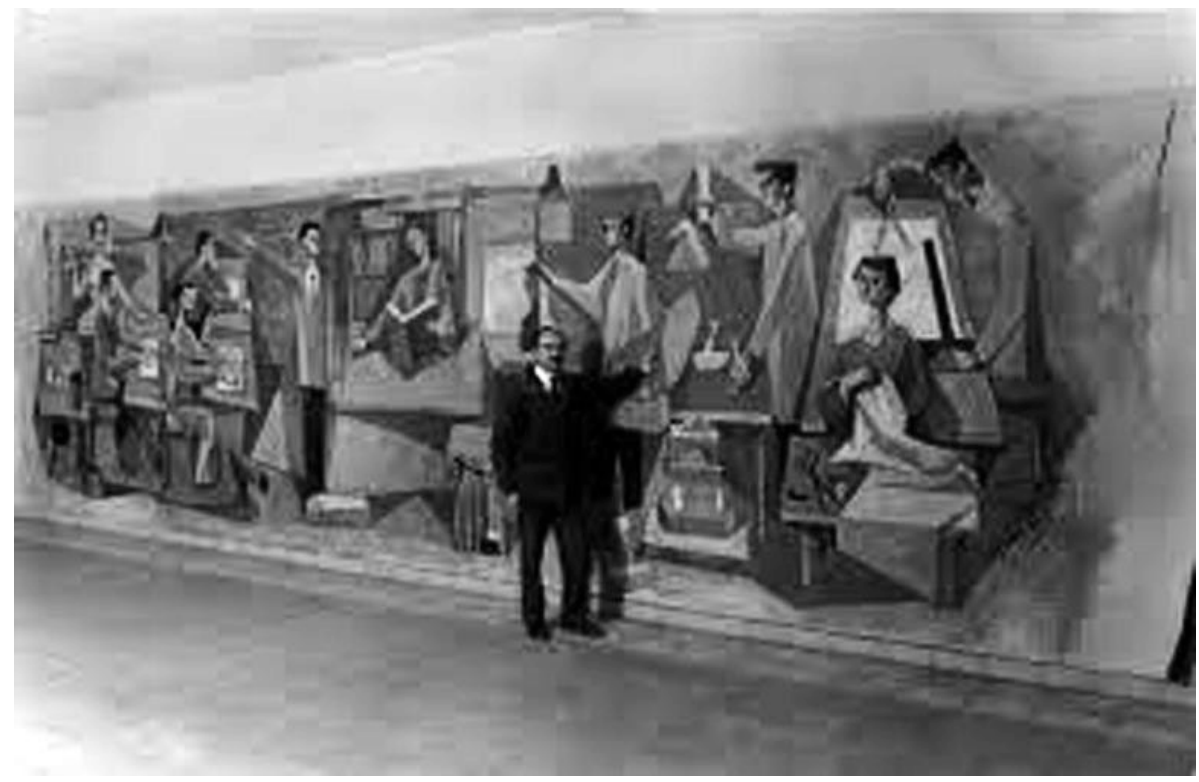

LÁmina. 3. El autor junto a su mural.

El centro de la composición está dominado por dos figuras que representan a un profesor de pie explicando en la pizarra y a su izquierda posiblemente una profesora leyendo sentada delante de una estantería llena de libros a modo de biblioteca. En cada extremo y de forma equilibrada se distribuyen cuatro figuras; en el lado izquierdo, dos masculinas y una femenina escuchan las explicaciones de clase y una joven sostiene una balanza; en el lado derecho aparecen tres hombres, realizando respectivamente prácticas de dibujo artístico, laboratorio y dibujo lineal, junto a una mujer ejecutando labores de costura. 
Asimismo, se distribuyen, sobre las mesas y principalmente por el suelo, varios objetos relacionados con las diversas asignaturas de la carrera; de izquierda a derecha encontramos diferentes útiles de medida, un telescopio, varios cuerpos geométricos, un capitel clásico, un busto, quizás un violín e instrumental de laboratorio. (Láminas 2 y de 6 a 9)

Sebastián resolvió la ejecución del mural a partir de una estructura simétrica con un marcado eje central y disponiendo un gran número de figuras sobre un espacio multifragmentado a base de cuadriláteros y triángulos que dan unidad a un conjunto muy arquitectónico. Estas formas ortogonales, que enmarcan a los personajes a modo de fondo y que se presentan frontalmente ante el espectador, se corresponderían con objetos como la pizarra, los mapas, la estantería de libros, los cuadros o un caballete.

Otros elementos, como la mayoría de las mesas y pupitres en perspectiva o los mismos fondos, conforman un conjunto de diagonales, muy del gusto del artista, que sirven para crear una profundidad que rompe el estatismo vertical de las figuras, al mismo tiempo que delimitan el espacio en campos cromáticos o dirigen al espectador a través de la obra, algo que logra con el movimiento de los brazos.

La asimilación de este lenguaje cubista, conforme a las nuevas tendencias que Ilegaban a España ${ }^{11}$, se refleja también en la construcción de las figuras y los objetos, ambos resueltos formalmente por medio de líneas rectas, volúmenes depurados, sombras geométricas y juegos diagonales, elementos que continuarán apareciendo en trabajos posteriores como en el mural del cine Boston $^{12}$.

Siguiendo las tendencias racionalistas, repite el modelo figurativo que ya había empleado en los murales de la parroquia de Nuestra Señora de la Fuensanta $^{13}$, de personajes estilizados, esquemáticos, geométricos e impersonales en rasgos y facciones.

El tono sereno de la obra intenta romperlo con la variación posicional de las figuras (frontal, de perfil o de tres cuartos), con la utilización de diagonales e incluso alguna línea curva, así como con el acertado juego de miradas que lleva a desplazarse desde el centro hacia los extremos ininterrumpidamente.

11. Clérigues Peris, M. V., El Lenguaje Plástico en..., op. cit., p. 140. Muchos pintores que hacían pintura decorativa en los años cincuenta, influenciados por las técnicas cubistas y constructivistas, hicieron composiciones geometrizantes a base de tintas planas.

12. Imagen del mural delCineBoston: http://pintura.aut.org/BU04?Empnum=15577\&Inicio= 486 (Consulta: 22/08/2016).

13. La parroquia de Nuestra Señora de la Fuensanta se encuentra en el barrio del mismo nombre de la ciudad de Valencia; sus murales fueron realizados en 1958. 
Para delimitar los contornos prevalece la técnica del contraste cromático, lo cual le acerca más a su faceta pictórica que a su formación como cartelista cinematográfico y rotulista, pese a ello cuando quiere remarcar las luces y las sombras de algunos contornos dibuja líneas negras o blancas de una manera muy suelta.

El mural despliega una paleta de colores muy luminosa basada principalmente en dos gamas de tonos, una cálida de ocres claros y otra fría de azules, verdes y grisáceos que dan al conjunto una gran uniformidad. El lenguaje constructivo que utiliza en los contornos de las formas se repite en la formación de sus volúmenes que son muy facetados, con múltiples planos geométricos de luces y sombras creados a partir de un mismo tono de color que como cristales traslúcidos destacan los elementos que quedan atrapados en su interior al mismo tiempo que modifican sus colores.

El fondo funciona principalmente con tonos azulados y grises dejando el resto de tonos para las figuras y los objetos. En él dispone una pincelada más suelta que en el esto del mural e incluso se permite brochazos y goteados muy expresionistas. (Láminas 6 a 9)

\section{Situación actual}

Desde la inauguración de la Escuela Superior de Magisterio de Logroño o Escuela Normal "Juan Luis Vives" en el curso 1959-6014 las únicas reformas conocidas fueron las ejecutadas en los años 1968, 1970 y 1973'5, y fundamentalmente la remodelación definitiva, vinculada al traslado de la escuela de primaria aneja, que se efectuó entre los años 1993 y 1997, desarrollada, en varias fases, bajo la dirección del arquitecto Domingo García-Pozuelo Asins ${ }^{16}$.

Los trabajos llevados a cabo en el salón de actos consistieron en la transformación en un único espacio del patio de butacas y el escenario (utilizado en un primer momento como sala de lectura y posteriormente como sala de música) y en el aislamiento del anfiteatro y la cabina de proyección de la segunda planta para ser utilizados como aula magna.

14. Revista de educación. Ministerio de Educación Nacional. Vol. XLII nº 122 . Curso 1960-61, p. 67. http://www.mecd.gob.es/dctm/revista-de-educacion/1960/1960-122/1960re122cronica. pdf?documentld=0901e72b818901d7 (Consulta: 3/12/2016). En esta revista se recoge que en el curso 1959-60 se inauguraron los edificios de las Escuelas Superiores de Magisterio de Albacete, Castellón, Logroño, Lérida, Málaga y Orense.

15. AMLO, 12709/1 Reforma de la escuela aneja (creación de aulas, emplazamiento escalera a planta superior, cambio de duchas por wc, etc.), año 1970; 12709/1 Informe ${ }^{\circ} 122$ de 5 de abril de 1972 en el que el director de la Aneja solicita al Ayuntamiento de Logroño varios arreglos menores; 12709/1 Proyecto de pavimentación de patios, año 1973. En el AMLO se conservan también los proyectos del frontón y del polideportivo.

16. AMLO, 1007/93; 969/94 y 184/97. 
En origen, el salón de actos se extendía desde la primera a la tercera plantas del cuerpo central del edificio, encontrándose la pintura mural a la altura de la tercera planta.

Comparando el escenario del salón de actos que aparece en la Lámina 1 con el de las fotografías proporcionadas por Domingo García-Pozuelo antes de su intervención, puede apreciarse que anteriormente el techo fue rebajado, con un falso techo tipo Amstrong, hasta la moldura de madera que enmarcaba la escena en su parte superior.

En los planos de sección del proyecto de reforma, se constata que la altura de la platea era de 7,37 metros y que desde el techo primitivo hasta el rebaje hay una diferencia de 2,78 metros. En la reforma de 1993 el techo volvió a rebajarse, sin modificar el existente, con un nuevo falso techo acústico tipo Amstrong, en 1,47 metros quedando la nueva sala con una altura de 5,90 metros. (Láminas 4 y 5).

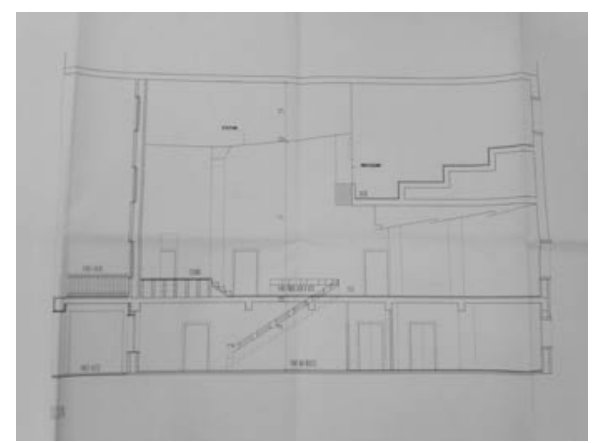

Lámina 4. Alzado original del salón.

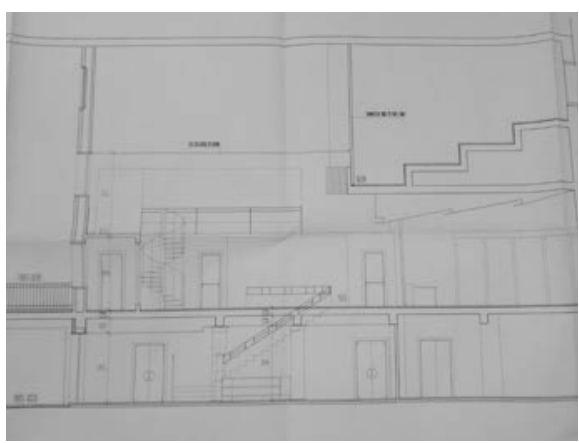

Lámina 5. Alzado proyecto 1993-97.

En un momento indeterminado, probablemente durante los años ochenta, se efectuó una reducción de la altura del patio de butacas, hasta la línea de arranque del mural en el límite superior del escenario, que ocultó la pintura objeto de este estudio en ese espacio de 2,78 metros $^{17}$.

Gracias a la ayuda de Rodrigo Asenjo, aparejador de la Universidad de La Rioja, se ha podido confirmar que el mural se encuentra todavía en su lugar de de origen, oculto por los dos techos añadidos, en un espacio estanco de unos 4,25 metros, a la altura de la tercera planta del bloque central.

17. En los archivos del Ayuntamiento de Logroño, de la Universidad de La Rioja y de la Universidad de Zaragoza y el General de La Rioja no se ha encontrado documento anterior a 1993 que permita concretar la fecha en la cual se produjo el rebaje del techo, posiblemente pudo llevarse a cabo sin solicitar licencia. 

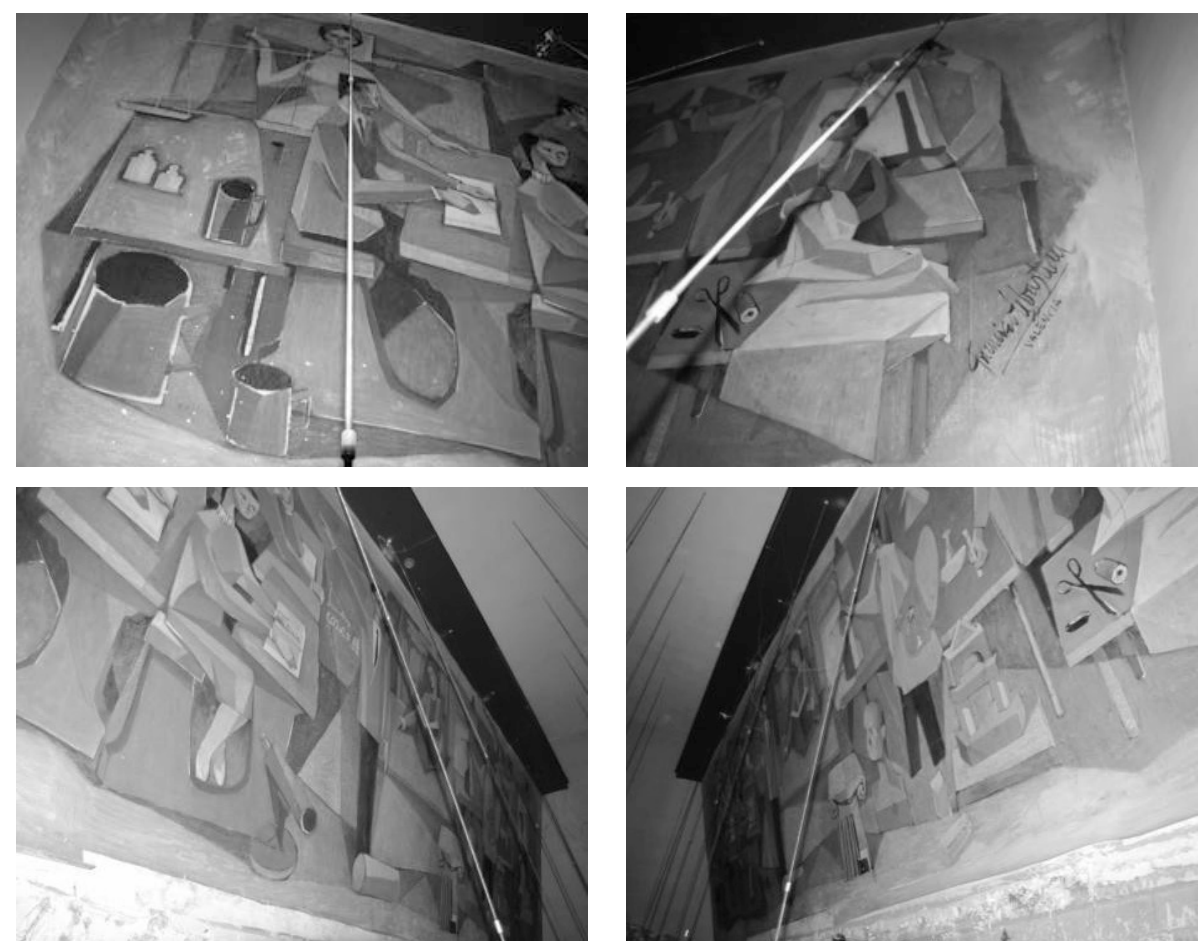

LÁminas 6 a 9. Estado del mural en 2017.

\section{El autor y su obra}

Francisco Sebastián Rodríguez nació en Valencia en 1920 y falleció en esa misma tierra en 2013. Fue pintor, decorador, muralista, profesor y académico de número de la Real Academia de Bellas Artes de San Carlos de Valencia. En 2011 fue nombrado Hijo Predilecto de la Ciudad de Valencia ${ }^{18}$. Comenzó profesionalmente como rotulista de publicidad para salas de cine y vallas publicitarias, lo que le daría un gran dominio de los grandes formatos para la realización de sus posteriores murales. Se formó en 1933 en la Escuela de Artes y Oficios y en 1945 concluyó sus estudios en la en la Escuela de Bellas Artes, coincidió en las clases, entre otros, con Eusebio Sempere y Hernández Mompó ${ }^{19}$. También

18. Para la biografía del pintor pueden consultarse las siguientes referencias: Clérigues Peris, M. V., El Lenguaje Plástico en..., op. cit.; http://cultura.elpais.com/cultura/2013/01/14/ actualidad/1358120127_176482.html; http://www.20minutos.es/noticia/1735404/0/.

19. Clérigues Peris, M. V., El Lenguaje Plástico en... op. cit. p. 108. 
entabló amistad con el poeta José Hierro (que prologaría los catálogos de sus exposiciones de 1973 y 1977) y con el pintor Juan Genovés. Participó brevemente en el valenciano "Grupo Z"20.

Compaginó la tarea docente con trabajos de interiorismo, las exposiciones ${ }^{21}$ y la realización de murales (durante 25 años llevo a cabo numerosas obras en tiendas, cines, cafeterías, bares o viviendas unifamiliares) ${ }^{22}$.

Su estilo pictórico, muy diferente al empleado en sus realizaciones murales, estuvo, en sus inicios, alejado de la tendencia dominante del luminismo de Sorolla. Evolucionó hacia una pintura sintética que en su madurez le acercó a propuestas más informalistas y a una abstracción constructivista. El color y la luz sosegados sirven para construir unos paisajes con una profunda carga lírica donde prima el equilibrio y la armonía.

20. El grupo Z estuvo en activo de 1946 a 1949. En Valencia se formaron entre los años 50 y 60 otros grupos que buscaban recuperar las vanguardias y mostrar su oposición al régimen como El Grupo de los Siete" (1949-1953), el Grupo Parpalló (1957-1959) o "Estampa Popular", pero Francisco Sebastián quiso permanecer fiel a sus objetivos y no formó parte de ninguno de ellos.

21. "Un siglo de pintura valenciana 1884-1994. Intuiciones y propuestas", IVAM, Valencia, 1994. "La pintura valenciana desde la postguerra hasta el grupo Parpalló 1939-56", Diputación Provincial de Valencia, Museo de la Beneficencia, Valencia, 1996. Exposición antológica, Museo de Bellas Artes, Valencia, 1999. Obras en diferentes museos e instituciones: Museo Provincial de Bellas Artes de Valencia, San Pío V. Museo de Arte Contemporáneo de Villafamés, Castellón. Museo de la Imprenta y la obra gráfica. Monasterio Santa María del Puig, Valencia. Instituto Valenciano de Arte Moderno (IVAM). Museo Municipal de la ciudad, Valencia. Fundación Bancaja, Valencia. Diputación Provincial de Valencia. Real Academia de Bellas Artes de San Carlos de Valencia.

22. Cine Torrefiel, Cine Triunfo, Cafetería Balanza o su obra más comprometida, la ampliación del restaurante de la estación modernista del Norte en Valencia en 1976.

De las obras que aún permanecen Clérigues Peris destaca las siguientes: Fundiciones "Bronces Bayarri, Valencia, 1950. Farmacia Espejo, Valencia, 1954 (desaparecido). Zaguán de la vivienda $\mathrm{n}^{\circ} 13$ de la calle maestro Gonzalbo, Valencia, 1957. Murales de la parroquia de la Virgen de la Fuensanta, Valencia 1958. Escuela de Magisterio de Logroño, 1959-60. Mural para el pabellón de "Tododeporte", Castellón. 1970. Cine Boston, Valencia, 1972. Cine España, Valencia. 